\title{
Correspondence
}

\section{Restimulation with ECT}

Sir: I found the paper by Gee \& White (Psychiatric Bulletin, 1993, 17, 606-607) where they stress the need for a formal restimulation policy in ECT very useful as we are working on a similar policy. Timing of seizure duration should be viewed as a form of process outcome measure for the procedure but the confounding effect of muscle relaxant suggests that the cuff technique should also be routinely employed (Addersley \& Hamilton, 1953).

It should be stressed that the 25 seconds minimum is not based upon clinical outcome studies, and there has not as yet been a demonstration that actual seizure duration is clinically relevant, although the presence of a seizure is.

The American studies use EEG seizure measures, so if a minimum adequate fit duration is ever demonstrated, it will be shorter by at least $10 \%$ in the UK as we use motor seizure timings (Fink \& Johnson, 1982).

ADDERSLEY, D.J. \& HAMmTON, M. (1953) The use of succinylcholine in ECT. British Medical Journal, 19, 541-550.

FINK, M. \& Johinson, R.N. (1982) Monitoring the duration of electroconvulsive therapy seizures, Archives of General Psychtatry, 39, 1189-1 191.

CARL S. LITTLEJOHNS, Deeside Community Mental Health Team, Deeside, Clwyd CH5 4DD

\section{Care of people with a mental handicap}

Sir: In 'Psychiatric emergencies in people with a mental handicap' Psychiatric Bulletin, 1993, 17, 587-589) Dora Kohan write ... . A trained, experienced and harmonious community team, a well organised back-up service of generic hospital beds and admission-assessment units for mentally handicapped people will deal with emergencies effectively".

The question is how many satisfactory admission-assessment units (NHS) for the mentally handicapped are there? The running down of large hospitals for the mentally handicapped without developing adequate numbers of new NHS units, a range of community homes, incentive for training staff and managerial fragmentation diminish morale and make the service inadequate, unsatisfactory and unpopular.

The time has come for the College to give strong leadership and send an urgent signal to the Government to focus on mentally handicapped people with neuro-psychiatric problems who need health care in the NHS in new small accommodation with adequate numbers of beds and qualified staff.

Debabrata Chakraborti, Park Vlew Resource Centre, Kings Lynn, Norfolk PE30 5QD

\section{Audit of outcomes}

Sir: "And how his audit stands who knows save Heaven" (Hamlet, Act 3). It is now clear from the White Paper (DoH, 1989) and from subsequent injunctions that how a doctor stands will depend on how diligently he pursues self-audit in general and the audit of the outcome of his work in particular. Many of those who urge the virtue of outcome audit on us believe it to be easy. On two occasions in the last month. I have been told authoritatively that reliability is a 'scientific' issue and not one that should trouble us when determining clinical outcome. Although acknowledging the difficulties of assessing outcome, the College's preliminary report on medical audit (Psychiatric Bulletin, 1989, 13, 577-580) remarks "Clinical audit ... is not research as no hypothesis is tested". May I put a contrary view? Some might regard exploratory data analysis (Tukey, 1977) and the analysis of residuals (Herschel, 1849) as research although neither is necessarily preceded by any clearly formulated hypothesis. Conversely, auditing clinical outcomes is likely to entail a hypothesis. To take a 'simple' example: there may be differences in mean wound-healing times after operations by different surgeons. Before drawing any large conclusions, the null hypothesis that such differences are no more than a reflection of the intrinsic variation in wound-healing time would need consideration.

Wound-healing time is univariate, continuous and, being directly observable, manifest. The outcomes of interest to psychiatrists are much less tractable, being multivariate, usually ordinal and often latent. If this were not bad enough, the audit of outcomes will not have the protection against false inferences afforded by double-blind conditions and random allocation to treatment or to procedure.

I would suggest, therefore, that the audit of outcomes, far from being an investigation purged of the difficulties of research, is research of especial difficulty.

DePARTMENT OF HEALTH (1989) Working for Patients: Medical Audit. London HMSO. 
Herschel, Sir JoHn (1849) Quoted from Applied Regression Analysis (2nd edition). N.R. Draper \& H. Smith. Chichester: Wiley, 1981.

TUKEY, J.W. (1977) Exploratory Data Analysis. Addison Wesley.

D. H. MYERS, Shelton Hospital, Bicton Heath, Shrewsbury SY3 8DN

\section{Dosage information in the British National Formulary}

Sir: We write to add our wholehearted support to Ann Barker for raising various concerns about dosage information contained in the British National Formulary (BNF) and how they have come to be used. (Psychiatric Bulletin, 1993, 17, 557). For some time now, in relation to the use of lithium medication we have been airing similar concerns about BNF and MIMS (Monthly Index of Medical Specialities). Both publications set out their aims and scope in their preface, for rapid reference and for use as a prescribing guide. Nonetheless, the publications seem to acquire a legal standing as, for example, "BNF maximum". The contents should be accurate and up to date so as to enjoy professional confidence and credibility. Otherwise how else could one reconcile major differences between BNF and MIMS as in the maximum suggested dose of injection Depixol where BNF suggests a maximum of $400 \mathrm{mg}$ weekly and MIMS "up to $300 \mathrm{mg}$ every 2 weeks".

We are pleased that a Royal College Consensus Group is looking into these issues. The group may wish to examine the accuracy and current validity of relevant entries in BNF and MIMS so that medical practitioners are better informed and their patients better served let alone legal implications. Regarding lithium medication, the problem is with dose, side effects, toxicity and contra-indications, for which the information is outdated and sometimes conflicting. The Third British Lithium Congress held in Wolverhampton in September 1992 established a working group to produce a consensus report on proposed guidelines for good clinical practice to deal with the problems out of date information in the BNF and MIMS. (Lithium Prophylaxts: Proposed Guidelines for Good Clinical Practice. (Report of a working party established by the Third British Lithium Congress, Wolverhampton 6-10 September 1992). N.J. Birch (Chairman of the Working Party), P. Grof, R.P. Hullin, R.F. Kehoe, M. Schou and D.P. Srinivasan. Lithium, 4, November 1993).

D.P. SRINIVASAN, Garlands Hospital, Carlisle CA1 3SX; and N.J. BIRCH, Blomedical Research Laboratory, School of Health Sclences, University of Wolverhampton, Wolverhampton WV1 1DJ

\section{GPs' views of psychotherapy services}

Sir: I was interested to read the paper by Morton \& Staines on 'GP use of psychotherapy services' (Psychiatric Bulletin, 17, 526-527). I agree that little is known about how GPs view psychotherapy services, and heartened to see that, despite the ideological and organisational changes imposed on the NHS of late, the results indicate that GPs continue to value NHS psychotherapy services. My own study of GPs' views of psychotherapy services in Central Manchester in 1984-85 demonstrated a high degree of GP support for the services (95\%), and many wanted more contact with the services and opportunities for further training and supervision for themselves (Reilly, 1987). There was a clear need for dialogue between GPs and psychotherapists then, and no doubt the need is greater now, with general practice fund-holding and the need of provider units to attract referrals.

In York we are currently conducting a simple audit of GPs views and utilisation of the local NHS counselling and psychotherapy service. No doubt psychotherapy units around the country have or will be planning to do the same. It would be interesting to compare notes.

RELLY, S.P. (1987) A psychotherapy service: how general practitioners see it. Bulletin of the Royal College of Psychiatrists, 11, 191-192.

STEPHEN REILLY, Bootham Park Hospital, York YO3 7BY

\section{'Bulletin' readership survey}

Sir: Tom Fahy should be congratulated on his excellent survey and his courage in publicly challenging the editorial policy of the widely loved and respected Bulletin (Psychiatric Bulletin, $1993,17,473-476)$. His survey suggests an easy method of lowering the increasing rate of rejection of articles submitted to the Bulletin. Stop publishing the interviews and use the space to publish what the punters want and read. His survey showed less than $20 \%$ of readers usually always read interviews, but almost $50 \%$ usually or always read Audit in Practice. In the same edition of the Bulletin an interview with Professor Leighton was eight pages long while my paper on audit was only two pages (Hodgson et al, 478479). Excluding the intervlew would have provided four time as much space for similar audit articles of the same length, or the opportunity for $96 \%$ of the readership to read original papers or research reports.

OLA JUNAID, Nottingham Healthcare Unit, Mapperley Hospttal, Nottingham NG3 6AA 